American Journal of Pharmacology and Toxicology 5 (1): 24-33, 2010

ISSN 1557-4962

(C) 2010 Science Publications

\title{
Quercetin, Quercetrin Except Rutin Potentially Increased Pirarubicin Cytotoxicity by Non-Competitively Inhibiting the P-Glycoprotein-and MRP1 Function in Living K562/adr and GLC4/adr Cells
}

\author{
${ }^{1}$ Winit Choiprasert, ${ }^{1}$ Nathupakorn Dechsupa, ${ }^{1}$ Suchart Kothan, \\ ${ }^{2}$ Manuel Garrigos and ${ }^{1}$ Samlee Mankhetkorn \\ ${ }^{1}$ Laboratory of Physical Chemistry, Molecular and Cellular Biology, \\ Center of Excellence for Molecular Imaging, Department of Radiologic Technology, \\ Faculty of Associated Medical Sciences, Chiang Mai University, Chiang Mai 50200, Thailand \\ ${ }^{2}$ Department of Structural Biology and Bioenergetics Mechanisms, Commission for Atomic Energy, \\ Institute of Biology and Technologies-Saclay, Gif-sur-Yvette, F-91191, France
}

\begin{abstract}
Problem statement: Quercetin and its glycoside derivatives are increasingly receiving interests as new generation of anticancer molecules and were recognized by multidrug resistant transporters such as P-glycoprotein and MRP1 protein. Of relevance to their use as anticancer agents alone or in combination with other agents, this study aims to analyze the interaction of the compounds with the MDR transporters including P-glycoprotein and MRP1 protein in living multidrug resistant cells. Approach: The potential MDR reversing action of flavonoids was assessed by using the cotreatment of anticancer drug, pirarubicin or daunorubicin and quercetin, quercetrin or rutin compared with the series of co-treatment of pirarubicin or daunorubicin and the known inhibitor such as cyclosporine A and verapamil. The evidence of direct interaction of molecules with MDR protein was investigated by measuring the ability of inhibition of the rate of P-glycoprotein- and MRP1mediated efflux of pirarubicin out of cells. Results: Quercetin and its glycoside derivatives efficiently inhibited cancer cell proliferation and re-sensitize the MDR cells to pirarubicin but not for daunorubicin. Our results clearly show that quercetin, quercetrin except rutin non-competitively inhibited the function of P-glycoprotein in K562/adr and MRP1 in GLC4/adr cells. The determined $\mathrm{K}_{\mathrm{I}}$ value of P-glycoprotein was equal to $0.33 \mu \mathrm{M}$ for quercetin and $1 \mu \mathrm{M}$ for quercetrin and $\mathrm{K}_{\mathrm{I}}$ value of MRP1 was equal to $0.45 \mu \mathrm{M}$ for quercetin and $0.5 \mu \mathrm{M}$ for quercetrin. Conclusion: The overall results demonstrated that quercetin, quercetrin and rutin should be considered as potential pharmaceutical molecules that might be used as MDR inhibitors.
\end{abstract}

Key words:Quercetin, quercetrin, rutin, multidrug resistance phenomenon, MDR reversing activity, spectrofluorometry, co-treatment

\section{INTRODUCTION}

Bioflavonoids such as quercetin, apigenin and kaempferol are increasingly receiving interests as new generation of anticancer molecules due to their antioxidant and cancer apoptosis induction activity (Kothan et al., 2004; Dechsupa et al., 2007; Galati and O'Brien, 2004; Jeong et al., 2009; Tan and Swain, 2002). These researchers made evidence that how an antioxidant molecule could be potentially anticancer molecule of both in vitro studies using cells and in vivo studies using rat bearing cancer tissue as models. Because these flavonoids are potent antioxidants, their presence in the cytosol of cells should cause dramatically alteration the redox state of the cells by depleting the intracellular Reactive Oxygen Species $\left(\mathrm{ROS}_{\mathrm{i}}\right)$ and Reactive Nitrogen Species (RNS) were reported (Chaiswing et al., 2007; Pelicano et al., 2004; Sriburee et al., 2009). Recently, it was shown that after addition of quercetin, apigenin, kaempferol or eriodyctiol in to cancer cells (Kothan et al., 2004); the four flavonoids diffused across the plasma membrane

Corresponding Author: Samlee Mankhetkorn, Laboratory of Physical Chemistry, Molecular and Cellular Biology, Center of Excellence for Molecular Imaging, Department of Radiologic Technology, Faculty of Associated Medical Sciences, Chiang Mai University, Chiang Mai 50200 Thailand Tel: 6653949305 Fax: 6653213218 
into the cytosol of cells and immediately depleted the $\mathrm{ROS}_{\mathrm{i}}$ contents. However, the same concentration of these flavonoids did not affect the redox state of normal peripheral blood mononuclear cells. These findings suggest the differential maintenance of $\mathrm{ROS}_{\mathrm{i}}$ of cancer and normal cells. Since the normal cells maintain the redox state more efficiently than those of cancer cells (Chaiswing et al., 2007; Pelicano et al., 2004), thus the antioxidant molecules whose concentration mediated cytotoxicity in cancer cells did not possess the effects in normal cells. Moreover, the intact molecule of flavonoids mediates the anticancer activity by apoptosis induction via the mitochondrial pathway. We have recently reported that, beside their efficient antioxidant activity, quercetin, apigenin, kaempferol and eriodyctiol also efficiently inhibited cell growth of various cancer cell types including breast cancer MDA-MB 435, erythromyelogenous leukemic K562, small cell lung carcinoma GLC4 cells (Suttana, 2009). The particular interests are these flavonoids mediated almost the same antiproliferation efficacy in multidrug-resistant cancer cells such as K562/adr which over-expressed P-glycoprotein and GLC4/adr which over-expressed MRP1 protein when compared with their corresponding drug-sensitive cells (Tungjai et al., 2008).

The flavonoids were also reported to be recognized by MDR transporters especially P-glycoprotein and MRP1 protein (Choi et al., 2004; Hooijberg et al., 1997; Versantvoort et al., 1994; Ofer et al., 2005; Lania-Pietrzak et al., 2005). Among flavonoids, genistein is the first flavonoid that was found to be a potent inhibitor of MRP1 (Hooijberg et al., 1997; Versantvoort et al., 1994). It was reported that unfortunately their similar chemical structures, some isoflavonoids such as genistin did not inhibit ATPase activity but some such as genistein, kaempferol, flavopiridol affected the ATPase activity of GLC4/adr cells (Versantvoort et al., 1994). In addition, the direct interaction of some flavonoids with recombinant Nucleotide Binding Domain (NBDs) of human Pglycoprotein and MRP 1 were reported (Trompier et al., 2003). These authors also mentioned that the inhibition of MRP1-mediated efflux of anticancer drug by flavonoids should be due to a direct interaction with MRP1. These studies lead us to consider the flavonoids as chemosensitizers which have advantages of specific action without side effects.

Since the MDR transporters such as P-glycoprotein and MRP1 are belonging to ABC protein family consist of at least two substrate-binding sites which recognizes a wide spectrum of substrates. Indeed, some flavonoids depending on their chemical structures probably interact with the cytosolic domains of P-glycoprotein and MRP1 as well as their ATP binding site.

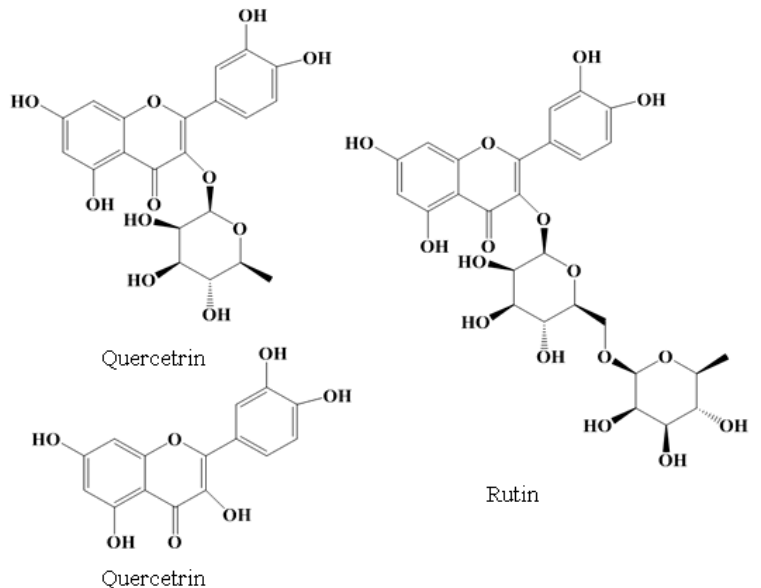

Fig. 1: Chemical structure of quercetin, quercetrin and rutin

However, rare studies reported on the inhibition of Pglycoprotein or MRP1 function related to the chemical structures of flavonoids in living MDR cells.

Therefore, this study aims to investigate the structure activity relationship of flavonoids on the MDR protein function in living MDR cell. For these purposes quercetin and its glycoside series by the esterification of rhamnose and rutinose at $\mathrm{C}^{3}$ position of ring $\mathrm{c}$ (for chemical structure Fig. 1) were used in this study. The potential MDR reversing action of flavonoids was preliminarily studied using co-treatment of pirarubicin or daunorubicin and quercetin, quercetrin or rutin. The interaction of these flavonoids with $\mathrm{P}$ glycoprotein and MRP1 protein were later rigorously analyzed. The results suggested that an esterification of rhamnoside and particular the rutinoside at $\mathrm{C}^{3}$ position of quercetin increased in by 3-flod their cytotoxicity in drug-sensitive but differential sensitivity in drugresistant cells. Quercetin and quercetrin except rutin non-competitively inhibited P-glycoprotein- and MRP1-mediated efflux of pirarubicin out of cells.

\section{MATERIALS AND METHODS}

Verapamil, cyclosporine A, quercetin $\left(3,5,7,3^{\prime}, 4^{\prime}\right.$ Pentahydroxyflavone), quercetin-3-rhamnoside or quercetrin (2-(3,4-dihydroxyphenyl)-5,7-dihydroxy-3[(2R,3R,4R,5R,6S)-3,4,5-trihydroxy-6-methyloxan-2-yl] oxychromen-4-one) and quercetin-3-rutinoside or rutin (3-[[6-O-(6-Deoxy-alpha-1-mannopyranosyl)beta-d-glucopyranosyl]oxy]-2-(3,4-dihydroxy-phenyl)5,7-dihydroxy-4H-1-benzo-pyran-4-one) were purchased from Sigma.

Daunorubicin and pirarubicin stock solutions were prepared in water just before used. Concentrations were 
Am. J. Pharm. \& Toxicol., 5 (1): 24-33, 2010

spectrophotometrically determined by diluting stock solutions in water to approximately $10 \mu \mathrm{M}$ and using $\varepsilon_{480}=11500 \mathrm{M}^{-1} \mathrm{~cm}^{-1}$.

HEPES-Na ${ }^{+}$buffer consists of $20 \mathrm{mM}$ HEPES buffer plus $132 \mathrm{mM} \mathrm{NaCl}, 3.5 \mathrm{mM} \mathrm{KCl}, 1 \mathrm{mM} \mathrm{CaCl}_{2}$ and $1.5 \mathrm{mM} \mathrm{MgCl}_{2}, \mathrm{pH} 7.25$ at $37^{\circ} \mathrm{C}$.

Cell lines, cell culture and cytotoxicity assay: The human erythromyelogenous leukemia cell line (K562) and its DOX-resistant, P-glycoprotein-overexpressing K562/adr subline, (Mankhetkorn et al., 1996; Tarasiuk et al., 1993) and the human small cell lung carcinoma cell line (GLC4) and its DOX-resistant, MRP1-overexpressing GLC4/adr subline (Reungpatthanaphong et al., 2003) were routinely cultured in RPMI 1640 medium supplemented with $10 \%(\mathrm{v} / \mathrm{v})$ fetal calf serum in a humidified atmosphere with $5 \% \mathrm{CO}_{2}$ at $37^{\circ} \mathrm{C}$. For the cytotoxicity assays, cells were plated at a density of $5 \times 10^{5}$ cell. $\mathrm{mL}^{-1}$ and used $24 \mathrm{~h}$ later $\left(8 \times 10^{5}\right.$ cell. $\left.\mathrm{mL}^{-1}\right)$ so that cells were in exponential growth phase. Cell viability was assessed by Trypan blue exclusion and cell number was determined with a haemocytometer.

The cytotoxicity assays were performed as follows: cells $\left(5 \times 10^{4} \mathrm{~mL}^{-1}\right)$ were incubated in the presence of various concentrations of drugs. The number of cells was then determined by flow cytometry. The concentration of drug required to inhibit cell growth by $50 \%$ after $72 \mathrm{~h}\left(\mathrm{IC}_{50}\right)$ was determined by plotting the percentage of cell growth inhibition versus the drug concentration. The Resistance Factor (RF) was defined as the $\mathrm{IC}_{50}$ of resistant cells divided by the $\mathrm{IC}_{50}$ of the corresponding sensitive cells (Mankhetkorn et al., 1996; Tarasiuk et al., 1993; Reungpatthanaphong et al., 2003).

The potential MDR reversing action of flavonoids was studied by using the co-treatment assays. This is based on the rationale that the cytoxicity of a substrate of P-glycoprotein or MRP1 protein can be potentiated by flavonoids and the percentage of growth inhibition was lesser than $15 \%$ by treatment with flavonoid whose concentrations can completely or partially inhibit the MDR proteins. The co-treatment using pirarubicin or daunorubicin with various concentrations of quercetin, quercetrin or rutin was performed as follows. Cells $\left(5 \times 10^{4} \mathrm{~mL}^{-1}\right)$ were incubated in the presence of various concentrations of pirarubicin or daunorubicin and fixed concentration of flavonoid at $0.5,1,2$, or $5 \mu \mathrm{M}$. The number of cells was then determined at $72 \mathrm{~h}$ later using a flow cytometer. The MDR reversing efficacy $(\alpha)$ of molecule to increase the efficacy of pirarubicin or daunorubicin on MDR cells was calculated by the following expression:

$$
\alpha=\left[\mathrm{IC}_{50}(\mathrm{R})-\mathrm{IC}_{50}(\mathrm{RQ})\right] /\left[\mathrm{IC}_{50}(\mathrm{R})-\mathrm{IC}_{50}(\mathrm{~S})\right]
$$

Where:

$\mathrm{IC}_{50}(\mathrm{R})=$ The concentration of drug that inhibit $50 \%$ of MDR cell growth

$\mathrm{IC}_{50}(\mathrm{RQ})=$ The concentration of drug that inhibit $50 \%$ of MDR cell growth in the presence of flavonoid

$\mathrm{IC}_{50}(\mathrm{~S})=$ The concentration of drug that inhibit $50 \%$ of drug-sensitive cell growth

The $\alpha$ values varied from $0-1 ; \alpha=0$ when the MDR cells are treated with pirarubicin or doxorubicin alone and $\alpha=1$ when quercetin, quercetrin or rutin can reverse $100 \%$ of MDR phenomena, resulting in the same $\mathrm{IC}_{50}(\mathrm{RQ})$ as that of drug-sensitive cell lines. The flavonoid concentration increases in the efficacy of pirarubicin or daunorubicin by $50 \%$ is defined as $\alpha_{0.5}$.

Kinetics of membrane protein transporter-mediated efflux of pirarubicin: The rationale and validation of our experimental set-up for measuring the kinetics of uptake and P-glycoprotein-mediated efflux of pirarubicin in cells has been extensively described (Mankhetkorn et al., 1996; Tarasiuk et al., 1993; Reungpatthanaphong et al., 2003; Meesungnoen et al., 2002; Laochariyakul et al., 2003). Briefly, $2 \times 10^{6}$ cells were incubated for $30 \mathrm{~min}$ in $2 \mathrm{~mL}$ of HEPES-Na ${ }^{+}$ buffer in the presence of $10 \mathrm{mM} \mathrm{NaN} N_{3}$ and in the absence of glucose, in $1 \mathrm{~cm}$ quartz cuvette, rigorously stirred at $37^{\circ} \mathrm{C}$. The fluorescence intensity of pirarubicin at $590 \mathrm{~nm}$ (excited at $480 \mathrm{~nm}$ ) was followed, as a function of time (Perkin-Elmer model LS 55 spectrofluorometer). The rate of uptake is determined by following the decrease of fluorescence intensity was observed during incubation with cells, is due to quenching of fluorescence after intercalation of pirarubicin between the base pairs of DNA. At the steady state, concentration of the neutral form of the free drug must be the same in the extracellular medium and cytosol. Where $\mathrm{pH}_{\mathrm{i}}=\mathrm{pH}_{\mathrm{e}}$, this mean that $\mathrm{C}_{\mathrm{e}}$, the extracellular concentration, is equal to $\mathrm{C}_{\mathrm{i}}$, the cytosolic free drug concentration. The addition at steady state of $5 \mathrm{mM}$ glucose gives rise to ATP synthesis via the glycolysis path way and after about $30 \mathrm{sec}$, to increase in the fluorescence signal due to the release of drug from the cells. The rate of efflux is determined from the slope of the tangent to the curve $F=f(t)$, where $F$ is the fluorescence intensity at $590 \mathrm{~nm}$, at the time point corresponding to the time $\left(\mathrm{t}_{\mathrm{glu}}\right)$ of the addition of glucose. This method allows measuring accurately the nuclear concentration of pirarubicin in steady state $\left(C_{n}\right)$, the initial rates of uptake $\left(\mathrm{V}_{+}\right)$and the kinetics of active 
Am. J. Pharm. \& Toxicol., 5 (1): 24-33, 2010

efflux $\left(\mathrm{V}_{\mathrm{a}}\right)$. By using pirarubicin, the steady state was reached within 30 ands. At the end of the experiments, cell viability was assessed by using trypan blue exclusion.

\section{RESULTS}

Cytotoxicity of quercetin, quercetrin and rutin: The cytotoxicity of compounds was indicated in Table 1. As can be seen, quercetin, quercetrin and rutin exhibited antiproliferation in K562, K562/adr, GLC4 and GLC4/adr cells; the $\mathrm{IC}_{50}$ values were in micromolar range. The nonglycoside quercetin has similar toxicity in drug-sensitive and drug-resistant cells while a conjugation of rhamnoside (quercetrin) and rutinoside (rutin) at $\mathrm{C}^{3}$ in ring $\mathrm{c}$ trend to increase and decrease in cytotoxicity in drug-sensitive and drug-resistant cells, respectively. It should be noted that pirarubicin is very high efficacy in $\mathrm{K} 562$ and GLC4 $\left(\mathrm{IC}_{50}\right.$ is about $7 \pm 2 \mathrm{nM}$ ) but it was recognized and pumped out from K562/adr cells by P-glycoprotein and from GLC4/adr by MRP1 protein. These are the origins of lower efficacy in MDR cells as a consequence of an increase in the IC50 values and RF values (6-11 fold) in K562/adr and GLC4/adr cells.

Quercetin, quercetrin and rutin enhanced cytotoxicity of pirarubicin against K562/adr and GLC4/adr cells: The potential MDR reversing action of flavonoids was primarily studied by using the cotreatment of anticancer drug, pirarubicin or daunorubicin and quercetin, quercetrin or rutin compared with the series of co-treatment of pirarubicin or daunorubicin and the known inhibitor of MDR protein transporters (cyclosporine A or verapamil) (Mankhetkorn and Garnier-Suillerot, 1998).

Cyclosporine $\mathrm{A}$ is an efficient inhibitor of both $\mathrm{P}$ glycoprotein and MRP1 protein, while verapamil is more specific to $\mathrm{P}$-glycoprotein and is considered as very poor substrate of MRP1 protein. Cyclosporine A $(0.5 \mu \mathrm{M})$ increased in cytotoxicity of pirarubicin by $100 \%$ in K562/adr and $61 \%$ in GLC4/adr cells. Verapamil (2 $\mu \mathrm{M})$ increased in cytotoxicity of pirarubicin by $60 \%$ in K562/adr but not in GLC4/adr cells.

The MDR reversing efficacy $(\alpha)$ of quercetin and its derivatives increased in cytotoxicity of pirarubicin by inhibiting the function of P-glycoprotein or MRP1 protein in K562/adr or GLC4/adr cells, respectively, was indicated in Table 2. It should be noted that quercetin exhibited similar efficacy on MDR reversing action in K562/adr or GLC4/adr cells while quercetrin and rutin have higher degree of efficacy in GLC4/adr cells.
Table 1: $\mathrm{IC}_{50}$ values of quercetin and its glycoside derivatives, pirarubicin for $\mathrm{K} 562$ and GLC4 cell lines determined in normoxic and hypoxic conditions. RF is resistance factor defined as the $\mathrm{IC}_{50}$ of drug-resistant cell divided by that of its corresponding drug-sensitive cells

\begin{tabular}{llrlr}
\hline Compounds & $\mathrm{IC}_{50(\mathrm{~K} 562)}(\mu \mathrm{M})$ & $\mathrm{RF}$ & $\mathrm{IC}_{50(\mathrm{GLC} 4)}(\mu \mathrm{M})$ & $\mathrm{RF}$ \\
\hline Quercetin & $23.0 \pm 3.0$ & 1.0 & $18.0 \pm 8.5$ & 1.0 \\
Quercetrin & 11.0 & 1.9 & $12.0 \pm 2.5$ & 4.8 \\
Rutin & $3 \pm 0.2$ & 11.6 & 4.0 & 14.8 \\
Pirarubicin & $9.0^{*}$ & 6.7 & $5.0 \pm 1.0^{*}$ & 6.0
\end{tabular}

*: The concentration of pirarubicin used is in $\mathrm{nM}$

Table 2: MDR reversing efficacy $(\alpha)$ of quercetin, quercetrin and rutin in K562/adr and GLC4/adr cells

\begin{tabular}{lll}
\hline & MDR reversing efficacy $(\alpha)$ \\
Compounds & K562/adr & GLC4/adr \\
\hline $2 \mu \mathrm{M}$ quercetin & $0.67 \pm 0.14$ & $0.62 \pm 0.10$ \\
$5 \mu \mathrm{M}$ quercitrin & $0.63 \pm 0.10$ & $0.51 \pm 0.29$ \\
$2 \mu \mathrm{M}$ quercitrin & $0.26 \pm 0.11$ & $0.56 \pm 0.21$ \\
$5 \mu \mathrm{M}$ quercitrin & $0.30 \pm 0.15$ & $0.66 \pm 0.08$ \\
$2 \mu \mathrm{M}$ rutin & $0.24 \pm 0.01$ & $0.49 \pm 0.09$ \\
$5 \mu \mathrm{M}$ rutin & $0.33 \pm 0.03$ & $0.52 \pm 0.11$ \\
\hline
\end{tabular}

The MDR reversing assays of similar conditions of experiments were performed but this time using daunorubicin and quercetin, quercetrin or rutin. All compounds used did not modify the cytotoxicity of daunorubicin in both K562/adr and GLC4/adr cells.

Effects of quercetin, quercetrin and rutin on the $P$ glycoprotein-and MRP1-mediated efflux of pirarubicin: Figure 2 shows the typical results of $1 \mu \mathrm{M}$ pirarubicin uptake by K562 and K562/adr cells. As can be seen that the drug-sensitive cells-pirarubicin system was reached at the steady about $20 \mathrm{~min}$ and at least $10 \mu \mathrm{M}$ quercetin, quercetrin or rutin did not caused a significant change in the fluorescence intensity of pirarubicin. This signifies that the applied of these compounds whose concentration lower than $10 \mu \mathrm{M}$ should not modify the nature of pirarubicin fluorescence and any modification of pirarubicin fluorescence should cause by the interaction of molecules with cells.

Determination of the plasma membrane Pglycoprotein-and MRP1-mediated efflux of pirarubicin: Because pirarubicin is a weak based molecule and is a substrate of P-glycoprotein and MRP1 proteins, it is very suitable for use as a molecular probe to investigate cellular distribution and $\mathrm{P}$ glycoprotein-and MRP1-mediated pumping of drug at the plasma membrane and intracellular vesicle membrane (Laochariyakul et al., 2003). Pirarubicin accumulated in both the nuclear compartment and acidic organelles, regardless of its concentration. We 
have previously reported that the dissociation rate constant, or the affinity of pirarubicin for cell nuclei, was about $3 \mu \mathrm{M}$. The suitable range of pirarubicin concentrations when using as a molecular probe to investigate the function of intracellar P-glycoprotein and MRP1 protein was in the range of 4-8 $\mu \mathrm{M}$. To apply this technique, the nuclei should be saturated with pirarubicin so that the minute amount of pirarubicin released can be detected by a change in fluorescence intensity. When P-glycoprotein or MRP1 protein on the plasma membrane plays predominant role in pumping pirarubicin from the cells an increase in fluorescence intensity should be observed.

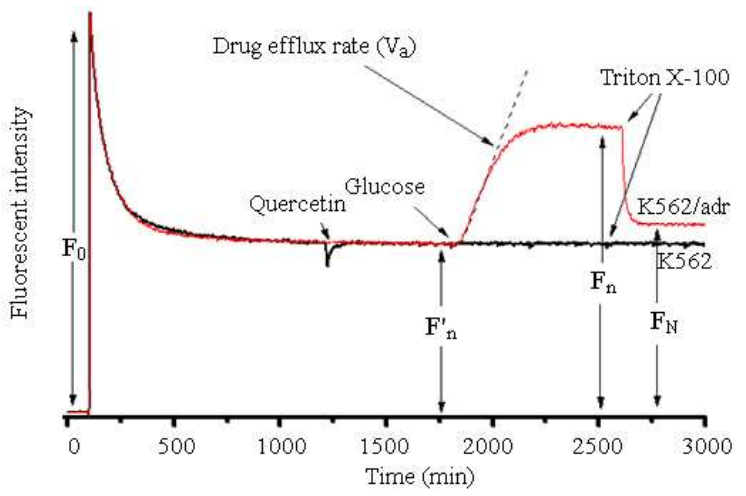

Fig. 2: Typical kinetics of pirarubicin uptake in K562 and deprived-energy K562/adr cells

Note: The fluorescence intensity at $\lambda_{\mathrm{em}}=590 \mathrm{~nm}\left(\lambda_{\mathrm{ex}}\right.$ $=480 \mathrm{~nm}$ ) was recorded as a function of time. Cells $\left(2 \times 10^{6}\right.$ cells $)$ were suspended in a cuvette filled with $2 \mathrm{~mL}$ HEPES-Na ${ }^{+}$, $\mathrm{pH} 7.25$ at $37^{\circ} \mathrm{C}$ under vigorous stirred. The cells were energy depleted by incubation with $\mathrm{NaN}_{3}$. At $\mathrm{t}=0$, a known concentration of pirarubicin was added to the cells, yielding a $\mathrm{C}_{\mathrm{T}} \mu \mathrm{M}$ pirarubicin solution. The fluorescence intensity was then $\mathrm{F}_{0}$ and $\mathrm{F}_{\mathrm{n}}$ or $F_{n}$ once the steady state was reached. After adding $10 \mu \mathrm{M}$ flavonoid no change in fluorescence intensity was observed. The following addition of $5 \mathrm{mM}$ glucose, which led to restoration of ATP synthesis and increased in fluorescence intensity in K562/adr cells because the efflux of pirarubicin, the fluorescence intensity was $F_{n}$ at the new steady state. The addition of Triton $\mathrm{X}-100$ yielded the equilibrium state, giving the fluorescence intensity of $F_{N}$. The overall cellular concentration $\left(\mathrm{C}_{\mathrm{n}}\right)$ and the overall nuclear concentration $\left(\mathrm{C}_{\mathrm{N}}\right)$ were determined as follows: $\mathrm{C}_{\mathrm{n}}=\mathrm{C}_{\mathrm{T}}\left(\mathrm{F}_{0}-\mathrm{F}_{\mathrm{n}}\right) / \mathrm{F}_{0}$ or $\mathrm{C}_{\mathrm{N}}=\mathrm{C}_{\mathrm{T}}\left(\mathrm{F}_{0}-\right.$ $\left.\mathrm{F}_{\mathrm{N}}\right) / \mathrm{F}_{0}$
Alternatively, when intracellular P-glycoprotein or MRP1 proteins play a predominant role in pumping pirarubicin into acidic organelles, a decrease in fluorescence intensity should be occurred as can be seen in Fig. 3.

Figure 4 shows the typical results of pirarubicin uptake (in the range of 7-9 $\mu \mathrm{M}$ ) in GLC4/adr cells. It should be noted that in the range of concentration used the nuclei were saturated. As we have been reported that the affinity of DNA to pirarubicin did not change, an amount of pirarubicin accumulated in the acidic organelles should indicate an entrapping process of weak base molecule inside the acidic organelles and these were completely disappeared when $20 \mathrm{nM}$ concanamycin A was added. Once the cells-pirarubicin system was reached to a steady state, $5 \mathrm{mM}$ glucose was added, an increase in pirarubicin fluorescence intensity was occurred, signifying that the functional MRP1 proteins were localized on the plasma membrane of GLC4/adr cells. The similar results were obtained for K562/adr cells.

Direct measurements of P-glycoprotein-and MRP1mediated efflux of pirarubicin out of cells in presence of quercetin, quercetrin and rutin: In order to analyze the direct interaction of flavonoids with plasma membrane P-glycoprotein or MRP1 proteins, the series of experiments were performed as follows. The uptake of pirarubicin was performed using the cells preliminarily treated using $10 \mathrm{mM} \mathrm{NaN}_{3}$ for $30 \mathrm{~min}$ with a fixed pirarubicin concentration at $0.5,1,4$ and $6 \mu \mathrm{M}$ and varied concentration of flavonoids were added at the steady state, $5 \mathrm{~min}$ before adding $5 \mathrm{mM}$ glucose. As can clearly be shown in Fig. 5 for the typical results of quercetin inhibited the function of Pglycoprotein in K562/adr (Fig. 5a) and MRP1 in GLC4/adr (Fig. 5b) cells. The rate of active efflux was directly measured, after addition of glucose to cells.

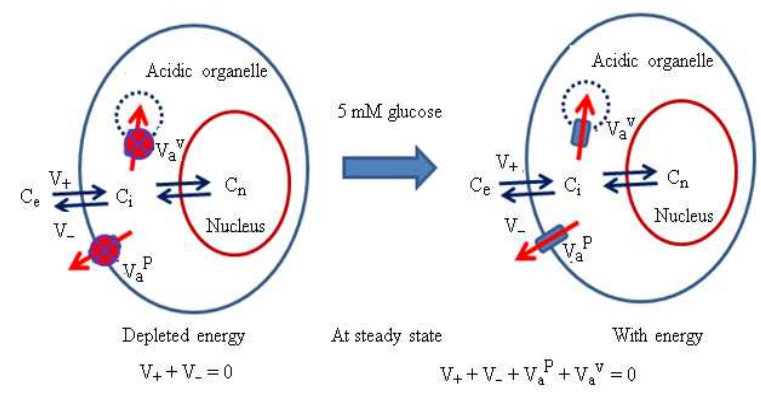

Fig. 3: Conceptual model of cellular distribution and MDR transporters mediated efflux of pirarubicin in GLC4/adr cells 
Am. J. Pharm. \& Toxicol., 5 (1): 24-33, 2010

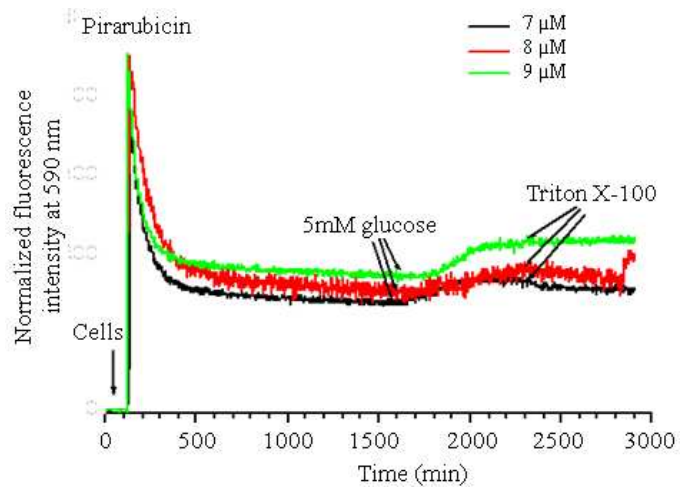

Fig. 4: Kinetics of pirarubicin uptake in deprivedenergy GLC4/adr cells

Note: The fluorescence intensity at $\lambda_{\mathrm{em}}=590 \mathrm{~nm}$ $\left(\lambda_{\mathrm{ex}}=480 \mathrm{~nm}\right)$ was recorded as a function of time. Deprived-energy cells $\left(2 \times 10^{6}\right.$ cells $)$ were suspended in a cuvette filled with $2 \mathrm{~mL}$ HEPES$\mathrm{Na}^{+}, \mathrm{pH} 7.25$ at $37^{\circ} \mathrm{C}$ under vigorous stirred. At $\mathrm{t}$ $=0$, a known concentration of pirarubicin was added to the cells, yielding a 7-9 $\mu \mathrm{M}$ pirarubicin solution. The fluorescence intensity was then $\mathrm{F}_{0}$ and $F_{n}^{\prime}$ once the steady state was reached. Upon adding of $5 \mathrm{mM}$ glucose, which led to restoration of ATP synthesis and increased in fluorescence intensity because the efflux of pirarubicin, the fluorescence intensity was $F_{n}$ at the new steady state. The addition of Triton X-100 yielded the equilibrium state, giving the fluorescence intensity of $\mathrm{F}_{\mathrm{N}}$

In these conditions, at the time $t_{\mathrm{glu}}$ corresponding to the addition of glucose, $\mathrm{C}_{\mathrm{i}}$ was equal to the extracellular drug concentration $\left(\mathrm{C}_{\mathrm{e}}\right) ; \mathrm{V}_{\mathrm{a}}$ and $\mathrm{C}_{\mathrm{i}}$ were directly determined and the data obtained have been plotted as $1 / \mathrm{V}_{\mathrm{a}}$ versus the concentration of quercetin, quercetrin or rutin (Fig. 6 and 7).

The results show that quercetin and quercetrin efficiently inhibited the function of P-glycoprotein and MRP1 with similar behaviors but rutin slightly did. These results also strongly suggested that quercetin and quercetrin except rutin non-compettively inhibit Pglycoprotein- and MRP1-mediated efflux of pirarubicin. The three straight lines fitted the plot of $1 / \mathrm{V}_{\mathrm{a}}$ as a function of the compound for experiments performed at constant pirarubicin, intersect $\mathrm{x}$-axis almost in the same point yielding $\mathrm{K}_{\mathrm{I}}$ of $\mathrm{P}$-glycoprotein was equal to $0.33 \mu \mathrm{M}$ for quercetin and $1 \mu \mathrm{M}$ for quercetrin and $\mathrm{K}_{\mathrm{I}}$ of MRP1 was equal to $0.45 \mu \mathrm{M}$ for quercetin and 0.50 $\mu \mathrm{M}$ for quercetrin. It should be noted that rutin did not exhibit the typical of neither competive nor noncompetitive inhibition.

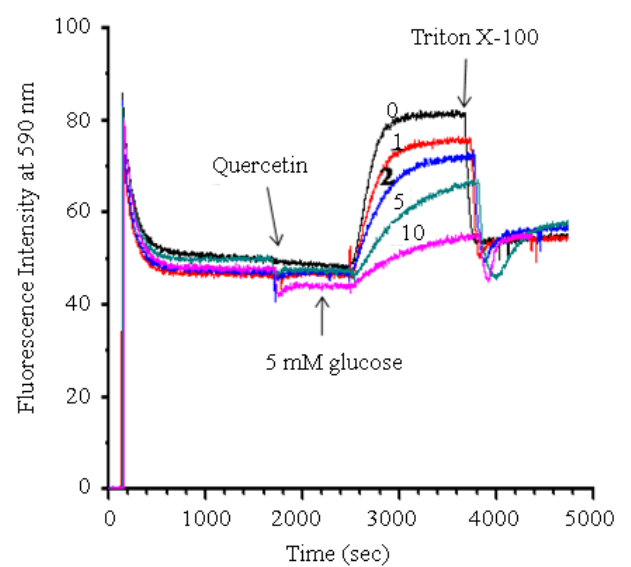

(a)

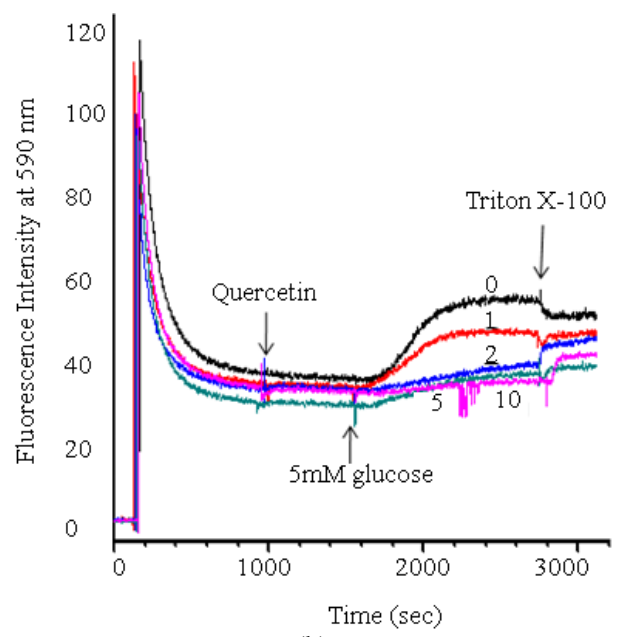

(b)

Fig. 5: Typical kinetics of pirarubicin uptake in deprived-energy K562/adr (a) and GLC4/adr (b) cells

Note: The fluorescenc e intensity at $\lambda_{\mathrm{em}}=590 \mathrm{~nm}$ $\left(\lambda_{\mathrm{ex}}=480 \mathrm{~nm}\right)$ was recorded as a function of time. Deprived-energy cells $\left(2 \times 10^{6}\right.$ cells $)$ were suspended in a cuvette filled with $2 \mathrm{~mL}$ HEPES$\mathrm{Na}^{+}, \mathrm{pH} 7.25$ at $37^{\circ} \mathrm{C}$ under vigorous stirred. At t $=0$, a known concentration of pirarubicin was added to the cells, yielding a $0.5 \mu \mathrm{M}$ pirarubicin solution. The fluorescence intensity was then $\mathrm{F}_{0}$ and $\mathrm{F}_{\mathrm{n}}$ once the steady state was reached. Varied flavonoid concentration ranging from $0-10 \mu \mathrm{M}$ was added following a successive addition of 5 $\mathrm{mM}$ glucose, which led to restoration of ATP synthesis and increased in fluorescence intensity in K562/adr cells because the efflux of pirarubicin, the fluorescence intensity was $F_{n}$ at the new steady state. The addition of Triton X100 yielded the equilibrium state, giving the fluorescence intensity of $F_{N}$ 


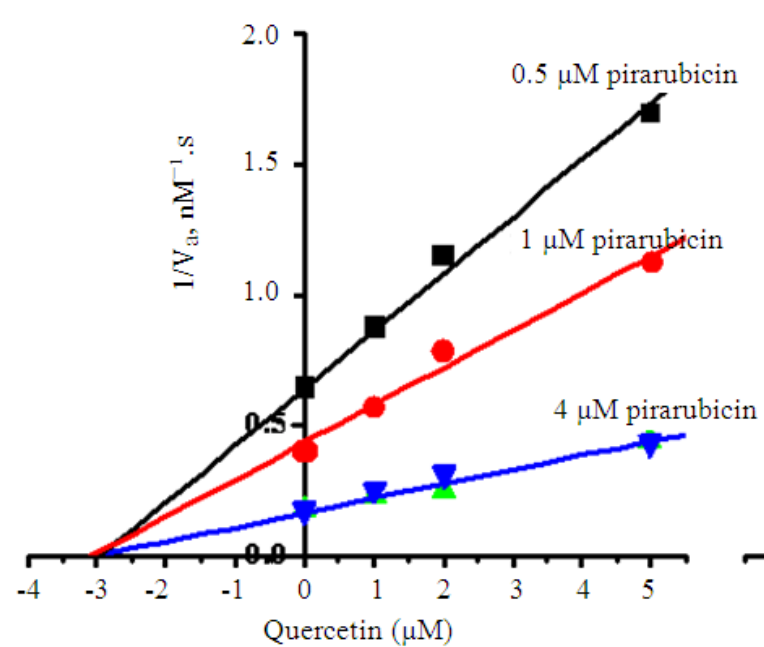

(a)

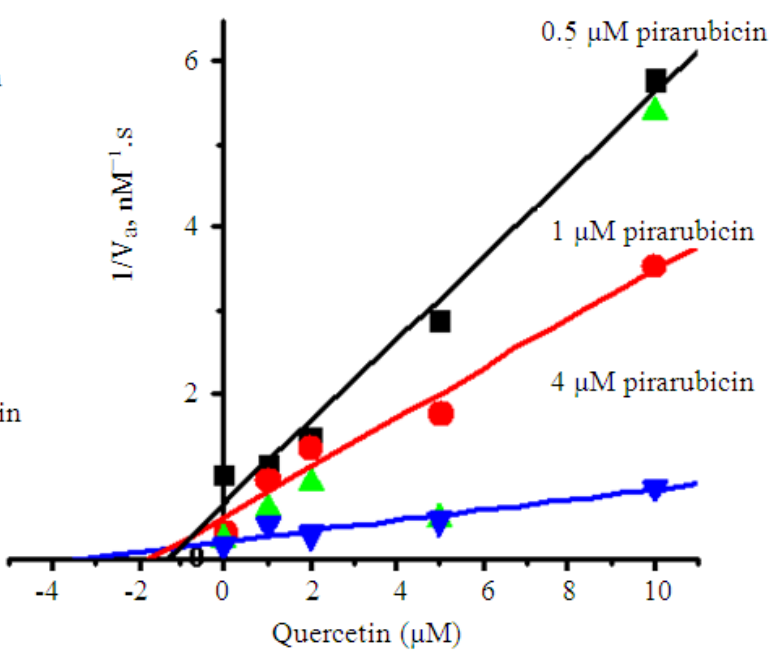

(b)

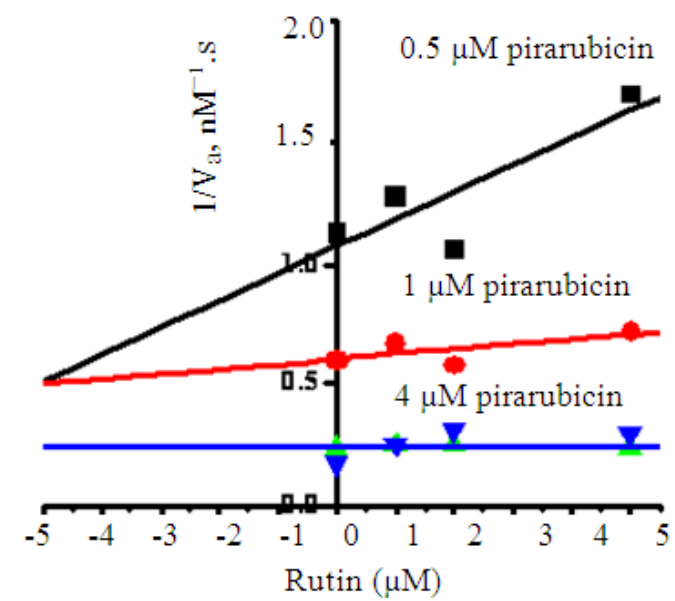

(c)

Fig. 6: Inhibition of P-glycoprotein-mediated efflux of pirarubicin by quercetin (a), quercetrin (b) and rutin (c). Variation of $1 / \mathrm{V}_{\mathrm{a}}$ has been plotted as a function of the flavonoid concentration. The straight lines are the linear least-square fits of the data

\section{DISCUSSION}

Quercetin, quercetrin and rutin are abundantly found in our daily foods. In addition to their antioxidant properties, a number of interesting activities have been described, especially their effects on cancer cell proliferation. Of relevance to their use as anticancer agents alone or in combination with other agents may be their interaction with the MDR transporters including P-glycoprotein and MRP1 protein which frequently expressed in human cancerous tissues. This study rigorously analyzed the kinetic parameters of Pglycoprotein- and MRP1-mediated efflux of pirarubicin in the presence of quercetin, quercetrin and rutin in living K562/adr and GLC4/adr cells. We thus firstly demonstrated that the treatment using quercetin, quercetrin and rutin alone efficiently inhibited cancer cell proliferation; particularly quercetin has almost the same activity in drug-sensitive and drug-resistant cells while the differential sensitivity was observed for quercetrin and rutin. However, among flavonoids studied, rutin was the most potent in drug-sensitive cells following quercetrin then quercetin. The results suggested that an esterification of rhamnoside and particular the rutinoside at $\mathrm{C}^{3}$ position of quercetin enormously increased in their cytotoxicity in drugsensitive but differential sensitivity in drug-resistant cells. 


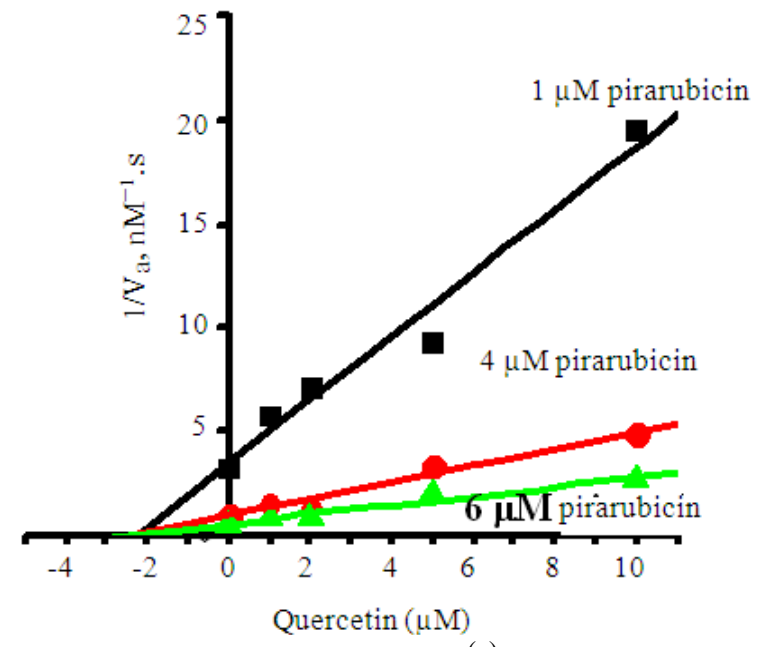

(a)

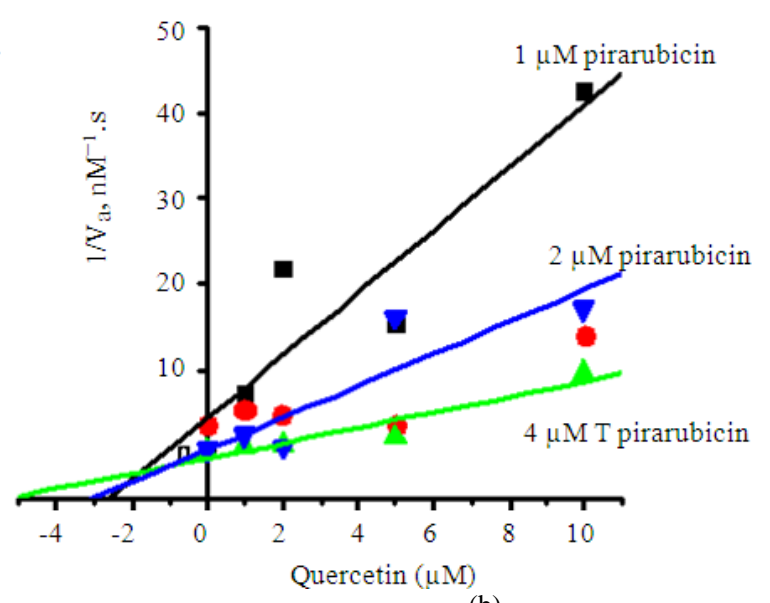

(b)

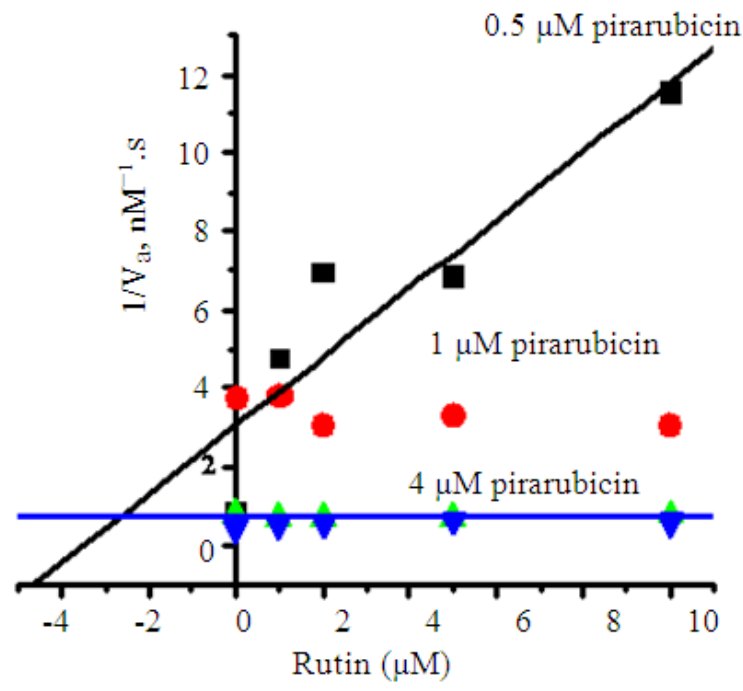

(c)

Fig. 7: Inhibition of MRP1-mediated efflux of pirarubicin by quercetin (a), quercetrin (b) and rutin (c). Variation of $1 / \mathrm{V}_{\mathrm{a}}$ has been plotted as a function of the flavonoid concentration. The straight lines are the linear leastsquare fits of the data

In order to understanding whether quercetin, quercetrin or rutin resensitized K562/adr and GLC4/adr cells to daunorubicin or pirarubicin via their direct interaction with the MDR transporters. It was verified that the applied concentration of the flavonoids did not inhibit cell growth of the cells. An increase in cytotoxicity of the anticancer drugs should be due to the direct interaction of quercetin, quercetrin or rutin with P-glycoprotein or MRP1 protein by which caused an increase in available intracellular concentration of anticancer drugs thus its cytotoxicity. Quercetin and quercetrin have affinity to P-glycoprotein or MRP1 protein similarly to cyclosporine A. It should be noted that quercetin, quercetrin and rutin increase in cytotoxicity of pirarubicin but not daunorubicin. Indeed, both daunorubicin and pirarubicin are known substrates of P-glycoprotein and MRP1 protein (Garnier-Suillerot et al., 2001); as can be expected that the anticancer drugs should be pumped out of cells by the transporters that required energy from ATP hydrolysis. If these flavonoids inhibited the ATPase activity of the two transporters, the kinetics parameters of transport of the two drugs should be found in similar way. The results suggested that quercetin, quercetrin or rutin should not inhibit the ATPase activity of both Pglycoprotein and MRP1 protein. The results also show 
that quercetin exhibited almost the same MDR reversing efficacy in K562/adr and GLC4/adr cells, but quercetrin and rutin exhibited more MDR reversing efficacy in MRP1 compared with P-glycoprotein phenotype.

To gain insight into the direct interaction of quercetin, quercetrin or rutin with the MDR transporters, the ability of inhibition of rate of $\mathrm{P}$ glycoprotein- and MRP1-mediated efflux of pirarubicin out of cells were analyzed. Since we have previously demonstrated that the intracellular MDR transporters were also found localized on the intracellular organelle membrane and they also play important role on pumping the drugs from cytosol into these organelles for example in SiHa cells (Laochariyakul et al., 2003; Mankhetkorn and Garnier-Suillerot, 1998; Dechsupa and Mankhetkorn, 2009). In this study we preliminary determined that for K562/adr and GLC4/adr cells, the functional P-glycoprotein and MRP1 protein was localized on the plasma membrane (GarnierSuillerot et al., 2001). Our results clearly show that quercetin, quercetrin except rutin non-competitively inhibited the function of P-glycoprotein in K562/adr and MRP1 in GLC4/adr cells. The determined $\mathrm{K}_{\mathrm{I}}$ value of P-glycoprotein was equal to $0.33 \mu \mathrm{M}$ for quercetin and $1 \mu \mathrm{M}$ for quercetrin and $\mathrm{K}_{\mathrm{I}}$ value of MRP1 was equal to $0.45 \mu \mathrm{M}$ for quercetin and $0.5 \mu \mathrm{M}$ for quercetrin. However, from these data it is difficult to distinguish between a purely non-competitive and mixed-type of inhibition. The results suggested that an esterification of rutinoside at $\mathrm{C}^{3}$ position of quercetin might change the transport behavior of the molecule.

Let consider the interaction of quercetin series as inhibitors on the substrate-binding sites for pirarubicin of P-glycoprotein and MRP1; (1) pirarubicin was 2 mole pumped out per turnover by $\mathrm{P}$-glycoprotein and MRP1 signified that there are two binding-sites for pirarubicin; (2) flavonoids should be recognized and bind on the two proteins at different binding-sites of those pirarubicin; (3) An esterification of rhamnoside at $\mathrm{C}^{3}$ position slightly increase in the affinity of molecule on both P-glycoprotein and MRP1 protein; and (4) an esterification of rutinoside at $\mathrm{C}^{3}$ position probably the rutinoside affected the molecular steric of quercetin thus changes the behavior of interaction of rutin with substrate binding sites.

\section{CONCLUSION}

The overall results demonstrated that quercetin and its glycoside derivatives efficiently re-sensitize the MDR cells to pirarubicin but not for daunorubicin. An esterification of rhamnoside at $\mathrm{C}^{3}$ position of ring $\mathrm{c}$ of quercetin slightly increased in affinity of molecule to its binding sites on P-glycoprotein and MRP1 protein. Both quercetin and its rhamnoside derivative noncompetitively inhibited the P-glycoprotein- and MRP1mediated efflux of pirarubicin. An esterification of rutinoside should be affected the molecular steric thus its nature of interaction with the MDR transporters but it still inhibits the function of P-glycoprotein and MRP1 protein. Quercetin, quercetrin and rutin should be considered as potential pharmaceutical molecules that might be used as MDR inhibitors.

\section{ACKNOWLEDGEMENT}

WC would like to thank the Commission on Higher Education, Ministry of Education Thailand for financial support. This work was financially supported by a grant funded under the Strategic Scholarships for Frontier Research Network for the Government, The Commission on Higher Education, Ministry of Education Thailand.

\section{REFERENCES}

Chaiswing, L., J.M. Bourdeau-Heller, W. Zhong and T.D. Oberley, 2007. Characterization of redox state of two human prostate carcinoma cell lines with different degrees of aggressiveness. Free Radic. Biol. Med., 43: 202-215. DOI: 10.1016/j.freeradbiomed.2007.03.031

Choi, C.H., J.H. Kim and S.H. Kim, 2004. Reversal of P-glycoprotein-mediated MDR by $5,7,3^{\prime}, 4^{\prime}, 5^{\prime}-$ pentamethoxyflavone and SAR. Biochem. Biophys. Res. Commun., 320: 672-679. DOI: 10.1016/j.bbrc.2004.06.020

Dechsupa, N. and S. Mankhetkorn, 2009. PGlycoprotein-Mediated efflux and drug sequestration in lysosomes confer advantages of k562 multidrug resistance sublines to survive prolonged exposure to cytotoxic agents. Am. J. Applied Sci., 6: 1637-1646. http://www.scipub.org/fulltext/ajas/ajas6916371646.pdf

Dechsupa, S., S. Kothan, J. Vergote, G. Leger and A. Martineau et al., 2007. Quercetin, siamois 1 and siamois 2 induce apoptosis in human breast cancer mda-mb-435 cells xenograft in vivo. Cancer Biol. Ther., 6: 48-53. DOI: 10.2174/1874126600802010010

Galati, G. and P.J. O'Brien, 2004. Potential toxicity of flavonoids and other dietary phenolics: Significance for their chemopreventive and anticancer properties. Free Radic. Biol. Med., 37: 287-303. DOI: 10.1016/j.freeradbiomed.2004.04.034 
Garnier-Suillerot, A., C. Marbeuf-Gueye, M. Salerno, C. Loetchutinat and I. Fokt et al., 2001. Analysis of drug transport kinetics in multidrug-resistant cells: Implications for drug action. Curr. Med. Chem., 8: 51-64. PMID: 11172692

Hooijberg, J.H., H.J. Broxterman, M. Heijn, D.L.A. Flesand and J. Lankelma et al., 1997. Modulation by (iso)flavonoids of the ATPASE activity of the multidrug resistance protein. FEBS Lett., 413: 344-348. PMID: 9280310

Jeong, J.H., J.Y. An, Y.T. Kwon, J.G. Rhee and Y.J. Lee, 2009. Effects of low dose quercetin: Cancer cell-specific inhibition of cell cycle progression. J. Cell Biochem., 106: 73-82. DOI: $10.1002 / j \mathrm{jcb} .21977$

Kothan, S., S. Dechsupa, G. Leger, J.L. Moretti and J. Vergote et al., 2004. Spontaneous mitochondrial membrane potential change during apoptotic induction by quercetin in K562 and K562/adr cells. Can. J. Physiol. Pharmacol., 82: 1084-1090. DOI: 10.1139/y04-113

Lania-Pietrzak, B., K. Michalak, A.B. Hendrich, D. Mosiądz and G. Grynkiewicz et al., 2005. Modulation of MRP1 protein transport by plant and synthetically modified flavonoids. Life Sci., 77: 1879-1891. DOI: 10.1016/j.lfs.2005.04.005

Laochariyakul, P., M. Ponglikitmongkol and S. Mankhetkorn, 2003. Functional study of intracellular P-gp- and MRP1-mediated pumping of free cytosolic pirarubicin into acidic organelles in intrinsic resistant SiHa cells. Can. J. Physiol. Pharmacol., 81: 790-799. DOI: 10.1139/Y03-061

Mankhetkorn, S. and A. Garnier-Suillerot, 1998. The ability of verapamil to restore intracellular accumulation of anthracyclines in multidrug resistant cells depends on the kinetics of their uptake. Eur. J. Pharmacol., 343: 313-321. DOI: 10.1016/S0014-2999(97)01548-3

Mankhetkorn, S., E. Teodori, S. Scapecchi and A. Garnier-Suillerot, 1996. Study of P-glycoprotein functionality in living resistant K562 cells after photolabeling with a verapamil analogue. Biochem. Pharmacol., 52: 213-17. DOI: 10.1016/00062952(96)00178-5

Meesungnoen, J., J.P. Jay-Gerin and S. Mankhetkorn, 2002. Relation between MDR1 MRNA levels, resistance factors and the efficiency of Pglycoprotein mediated-efflux of pirarubicin in multidrug resistant K562 sublines. Can. J. Physiol. Pharmacol., 80: 1054-1063. DOI: 10.1139/y02-132

Ofer, M., S. Wolffram, A. Koggel, H. Spahn-Langguth and P. Langguth, 2005. Modulation of drug transport by selected flavonoids: Involvement of PGp and OCT? Eur. J. Pharm. Sci., 25: 263-271. DOI: 10.1016/j.ejps.2005.03.001
Pelicano, H., D. Carney and P. Huang, 2004. ROS stress in cancer cells and therapeutic implications. Drug Resistance Updates, 7: 97-110. DOI: 10.1016/j.drup.2004.01.004

Reungpatthanaphong, P., S. Dechsupa, J. Meesungnoen, C. Loetchutinat and S. Mankhetkorn, 2003. Rhodamine $\mathrm{B}$ as a mitochondrial probe for measurement and monitoring of mitochondrial membrane potential in drug-sensitive and -resistant cells. J. Biochem. Biophys. Methods, 57:1-16. DOI: $10.1016 / \mathrm{s} 0165-022 \mathrm{X}$ (03)00032-O

Sriburee, S., H.J. Majima, H.P. Indo, K. Tomita and S. Mankhetkorn, 2009. Depletion of supper oxide anion radicals by increasion manganese superoxide sidmutase affected the growth pattern of normal and cancer gastric mucosal cell. Proceeding of the 35th Congress on Science and Technology of Thailand, Oct. 15-17, The Tride Resort (Bangsaen Beach), Chonburi, Thailand.

Suttana, W., 2009. Dissertation. Chiang Mai University, Chiang Mai, Thailand.

Tan, A.R. and S.M. Swain, 2002. Review of flavopiridol, a cyclin-dependent kinase inhibitor, as breast cancer therapy. Semin. Oncol., 29: 77-85. DOI: 10.1016/S0093-7754(02)70130-9

Tarasiuk, J., J. Foucrier and A. Garnier-Suillerot, 1993. Cell cycle dependent uptake and release of anthracycline by drug-resistant and drug-sensitive human leukaemic K562 cells. Biochem. Pharmacol., 45: 1801-1808. DOI: 10.1016/00062952(93)90436-Z

Trompier, D., H. Baubichon-Cortay, X.B. Chang, M. Maitrejean and D. Barron et al., 2003. Multiple flavonoid-binding sites within multidrug resistance protein MRP1. Cell Mol. Life Sci., 60: 2164-2177. DOI: 10.1007/s00018-003-3177-6

Tungjai, M., W. Poompimon, C. Loetchutinat, S. Kothanand and N. Dechsupa et al., 2008. Spectrophotometric Characterization of Behavior and the Predominant Species of Flavonoids in Physiological buffer: Determination of solubility, lipophilicity and anticancer efficacy. Open Drug Deliv. J., 2: 10-19.

Versantvoort, C.H.M., H.J. Broxterman, J. Lankelma, N. Feller and H.M. Pinedo, 1994. Competitive inhibition by genistein and ATP dependence of daunorubicin transport in intact MRP overexpressing human small cell lung cancer cells. Biochem. Pharmacol., 48: 1129-1136. DOI: 10.1016/0006-2952(94)90149-X 